\title{
ERRATUM
}

\section{Reforming East Asia for Sustainable Development}

Jomo K. S.

Asian Business \& Management (2003) 2, 297. doi:10.1057/palgrave.abm.9200038

Correction to: Asian Business \& Management (2003) 2, 7-38. doi: 10.1057/ palgrave.abm. 9200026

The publishers would like to apologize for the incorrect spelling of Professor Jomo's name on the contents page and title page of ABM vol 2, issue 1. We would also like to apologize for the duplication of Notes 1-6 (pp. 33-34). 